\title{
Absent or Extremely Low Neutrophil Alkaline Phosphatase Activity Levels in Patients with Myelodysplastic Syndromes
}

\author{
Yataro Yoshida ${ }^{1}$, Tatsuya Katsurada ${ }^{1}$, Shigeru Oguma ${ }^{1}$, Yukiharu Nakabo ${ }^{1}$, \\ Noriyoshi Yoshinaga ${ }^{2}$, Masahiro Kawahara ${ }^{2}$ and Hiroshi Kawabata ${ }^{2}$
}

\begin{abstract}
Three patients with myelodysplastic syndrome (MDS) had absent or extremely low levels of neutrophil alkaline phosphatase (NAP) activity (arbitrarily defined as an NAP score $<10$ ). All patients showed varying degrees of hypogranulation in neutrophil morphology. The NAP activity levels transiently normalized following the administration of granulocyte colony-stimulating factor (G-CSF) in two cases. No patients experienced any severe infectious episodes. These results suggest that NAP activity is not central to the neutrophil function.
\end{abstract}

Key words: neutrophil alkaline phosphatase, myelodysplasia

(Intern Med 52: 479-482, 2013)

(DOI: 10.2169/internalmedicine.52.9114)

\section{Introduction}

Myelodysplastic syndrome (MDS) is a diverse group of hematopoietic disorders characterized by dysplasia, peripheral cytopenia, and the risk of progression to acute myeloid leukemia and death. Cellular dysfunction and/or cytopenia of the neutrophilic lineage contribute to infections, a known cause of morbidity and mortality in patients with MDS (1). The neutrophil alkaline phosphatase (NAP) activity level is one of the practical measurements used to evaluate the neutrophil functions. We herein report three cases with absent or extremely low levels of NAP activity.

\section{Case Reports}

\section{Case 1}

An 81-year-old man presented with a progressive anemia ( $\mathrm{Hb} 8.1 \mathrm{~g} / \mathrm{dL}$ ). His white blood cell (WBC) and platelet counts were normal, although myelocytes (14\%) were present in the peripheral blood (PB), and the NAP activity was nil (Table). The patient's bone marrow (BM) was hypercellular with an M/E (myeloid/erythroid) ratio of 10.3. Marked hypogranulation with a pelgeroid nuclear chromatin pattern was seen in the myeloid series (Figure 1A), although blast cells accounted for only $1.6 \%$ of BM (Figure 1B). T( $3 ; 17$ ) (q26.2; 23 ) and +8 chromosomal abnormalities were present, in 18 and two metaphases, respectively, out of 20 metaphases examined. The WBC count subsequently rose to $140 \times 10^{3} / \mu \mathrm{L}$ and remained elevated thereafter. However, the number of blast cells showed no increases in either the PB or $\mathrm{BM}$. The predominant cell types were immature myeloid cells. Although BCR-ABL was not examined, a diagnosis of chronic myelogenous leukemia (CML) was excluded due to the cytogenetic findings. The patient was diagnosed as having myelodysplasia/myeloproliferative neoplasm (MDS/ MPN) according to the revised WHO classification (2). His IPSS-R (Revised International Prognostic Score) was high (3). He has been doing well under 5-azacytidine treatment and has shown a slight improvement in red cell transfusion dependence.

\section{Case 2}

An 83-year-old man was referred to us for an evaluation of macrocytic anemia. His laboratory data were as follows: $\mathrm{Hb}: 7.2 \mathrm{~g} / \mathrm{dL}, \mathrm{MCV}: 105 \mathrm{fL}, \mathrm{WBC}: 2.8 \times 10^{3} / \mu \mathrm{L}$, and platelets: $17.3 \times 10^{4} / \mu \mathrm{L}$. His neutrophil count was $33 \%$ with an ex-

${ }^{1}$ The Center for Hematological Diseases, Takeda General Hospital, Japan and ${ }^{2}$ Department of Hematology/Oncology, Graduate School of Medicine, Kyoto University, Japan

Received for publication October 11, 2012; Accepted for publication November 15, 2012

Correspondence to Dr. Yataro Yoshida, yoshida@takedahp.or.jp 
Table. Clinical, Laboratory and Neutrophil Cell Surface Characteristics of Patients

\begin{tabular}{|c|c|c|c|c|c|c|c|c|c|c|}
\hline \multirow{3}{*}{ Case } & \multirow{3}{*}{ Age \& Sex } & \multirow{3}{*}{$\begin{array}{l}\text { MDS } \\
\text { types }\end{array}$} & \multirow{3}{*}{$\begin{array}{c}\text { IPSS-R } \\
\text { risk }\end{array}$} & \multirow{2}{*}{\multicolumn{2}{|c|}{ NAP }} & \multicolumn{5}{|c|}{ Flow cytometric expression (PB neutrophils) } \\
\hline & & & & & & \multirow{2}{*}{$\begin{array}{c}\text { CD13 } \\
\%\end{array}$} & \multirow{2}{*}{$\begin{array}{c}\text { CD16 } \\
\%\end{array}$} & \multirow{2}{*}{$\begin{array}{c}\text { CD11c } \\
\%\end{array}$} & \multirow{2}{*}{$\begin{array}{c}\text { CD64 } \\
\% \\
\end{array}$} & \multirow{2}{*}{$\begin{array}{c}\text { CD114 } \\
\%\end{array}$} \\
\hline & & & & $\%$ & score & & & & & \\
\hline 1 & $81 \mathrm{M}$ & MDS/MPN & high & 0 & 0 & 55.9 & 63.1 & 51.7 & 27.9 & 29.3 \\
\hline 2 & $83 \mathrm{M}$ & RCMD & low & 4 & 8 & 99.3 & 99.8 & 87.5 & 96.5 & 97.3 \\
\hline 3 & $78 \mathrm{~F}$ & RCMD & intermediate & 3 & 3 & 96.6 & 97.8 & 99.8 & 63.2 & 98.9 \\
\hline
\end{tabular}

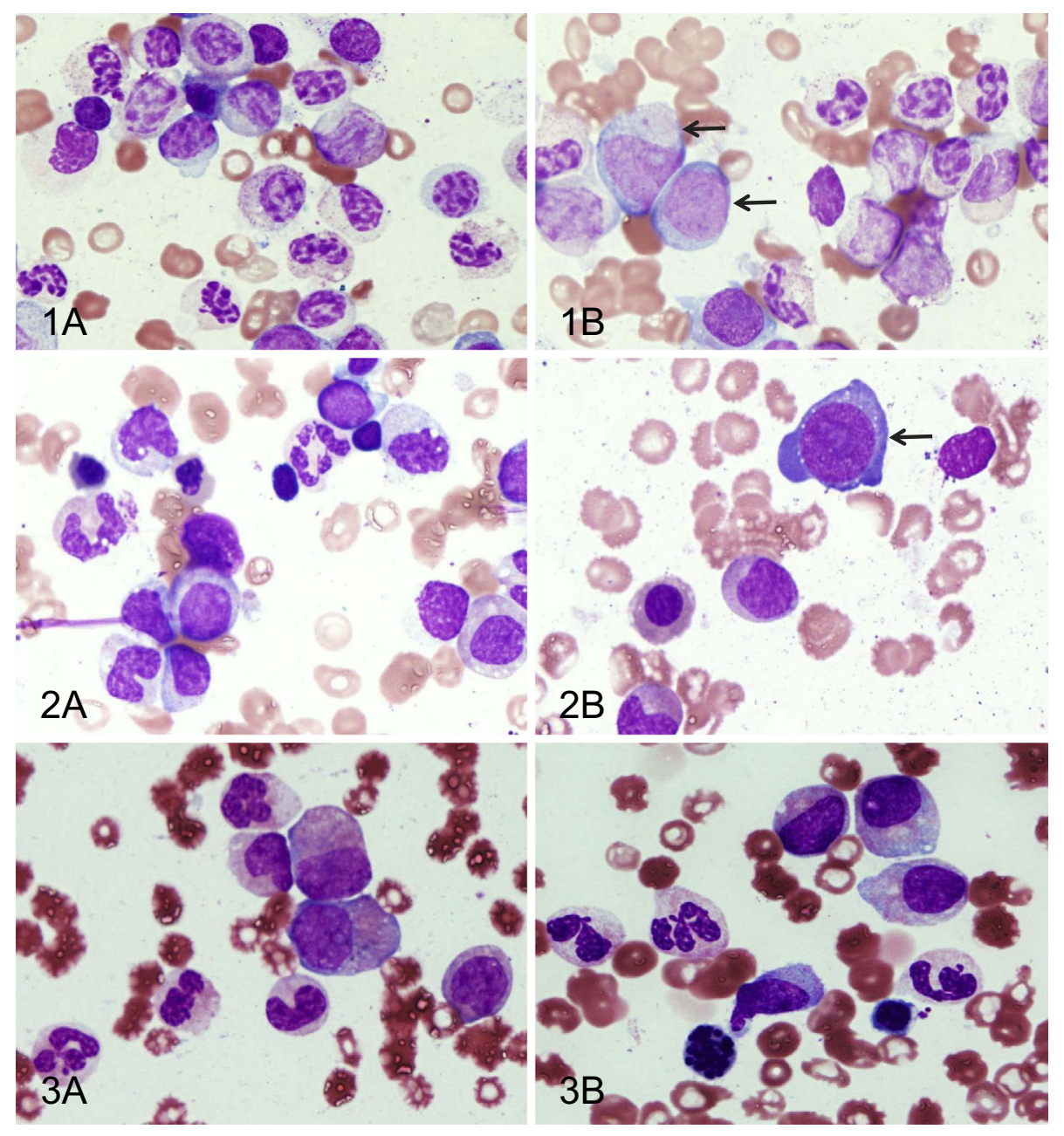

Figure. Photomicrographs of bone marrow smears stained with May-Giemsa. Original magnification $\times 1,000$. Profound hypogranulation and pelgeroid nuclear chromatin in the myeloid series in Case 1 (1A). The arrow indicates blast cells in Case 1 (1B). Hypogranulation in the myeloid cells (2A) and an erythroblast with megaloblastoid changes in Case 2 (arrow, 2B). Hypogranulation in both immature and mature myeloid cells $(3 \mathrm{~A}, 3 \mathrm{~B})$.

tremely low level of NAP activity (Table). Serum chemistry revealed a high erythropoietin level $(728.1 \mathrm{mIU} / \mathrm{mL})$ and normal levels of ferritin, B12, and folate. The patient's BM was cellular with an $\mathrm{M} / \mathrm{E}$ ratio of 11.77 and blast cells totaling $1.8 \%$. The myeloid cells showed varying degrees of hypogranulation (Figure 2A). Erythroid cells were sparse, although some megaloblastoid changes were found (Figure $2 \mathrm{~B}$ ). In addition, $15 \%$ of the erythroblasts were PAS positive. Dysplastic megakaryocytic cells such as micro- megakaryocytes and cells with multiple round nuclei were seen. The results of a cytogenetic study were normal. A diagnosis of refractory cytopenia with multilineage dysplasia (RCMD) (2) and a risk categorization of a low IPSS-R (3) was made. The patient has been given occasional red cell support.

\section{Case 3}

A 78-year-old woman had pancytopenia with an Hb level 
of $6.4 \mathrm{~g} / \mathrm{dL}$, a WBC count of $3.3 \times 10^{3} / \mu \mathrm{L}$ and a platelet count of $1.1 \times 10^{4} / \mu \mathrm{L}$. The neutrophil count was $44 \%$ with an extremely low level of NAP activity (Table). Her serum erythropoietin level was $72.3 \mathrm{mIU} / \mathrm{mL}$ and her ferritin level was $809 \mathrm{ng} / \mathrm{mL}$. Her BM was cellular with an $\mathrm{M} / \mathrm{E}$ ratio of 11.7 and blast cells totaling $0.2 \%$. Hypogranulation was seen in both immature and mature myeloid cells (Figure 3A, 3B). Some micromegakaryocytes were noted. A marrow cytogenetic study revealed trisomy 8 in all metaphases analyzed. A diagnosis of RCMD with an IPSS-R categorization of intermediate risk was made $(2,3)$. The patient has been given red cell and platelet transfusions.

All three patients showed an orderly expression of myeloperoxidase (MPO) as assessed with standard staining (data not shown).

\section{Discussion}

The abnormally low NAP activity levels observed in the present three cases were not due to technical errors, since the NAP activity levels remained unchanged in repeat examinations and in parallel examinations carried out at The Clinical Hematology Laboratories, Kyoto University Hospital. The control samples always yielded normal activity levels on each occasion.

The abnormal neutrophil functions present in patients with MDS reported to date include defective migration, superoxide production and microbial killing activity (4-6). The NAP activity shows no consistent pattern in MDS patients, although it is known to often be low. In fact, MDS is the only condition associated with decreased NAP scores besides CML, although the scores are not as low as those observed in CML (7). The present three MDS cases were unique in their extremely low levels of NAP activity, far lower than that observed in CML patients in the chronic phase. The NAP activity level has no significant correlation to the MPO activity level (7), as confirmed in the current report. A literature review found only two cases of MDS with extremely low NAP activity comparable to the present cases $(8,9)$. The case reported by Ohsaka et al. (8) involved absent levels of NAP as well as absent levels of complement receptor type 1, while the expressions of of other complement receptors, Fc receptors and adhesion molecules were normal. In our series, a flow cytometric evaluation of the PB neutrophils showed no consistent abnormalities in neutrophil cell surface markers, except for a somewhat reduced expression of the Fc $\gamma$ receptor (CD64) and the G-CSF receptor (CD114) in Case 1 (Table).

Absent NAP activity has been found in disease states other than MDS, either with (10) or without a history of recurrent infections (11). Obviously, NAP is not the sole microbicidal enzymes of neutrophils. Neutrophils contain MPO, as well as a large amount of other substances including lysozymes, NADPH oxidase, collagenase, lactoferrin and so on, all of which collaborate together to the fulfill neutrophilic microbicidal function. Clearly, a NAP defect by itself may be present in MDS patients with no relevance to susceptibility to infection unless associated with other functional defects of neutrophils.

Of interest is the effect of G-CSF on NAP activity. A single subcutaneous dose of $100 \mu \mathrm{g}$ of G-CSF resulted in the restoration of leukocytes and the NAP activity level in Cases 2 and 3. The WBC count rose to $12.7 \times 10^{3} / \mu \mathrm{L}$ on day 2 post-G-CSF in Case 2. The patient's NAP level rose to $89 \%$ with a score of 293 , and to $56 \%$ with a score of 143 , on days 2 and 4 post-G-CSF, respectively. Likewise, in Case 3, the patient reached a WBC count of $10.7 \times 10^{3} / \mu \mathrm{L}$ on day 2 post-G-CSF associated with a NAP rate of $74 \%$ and a score 218. Her NAP rate was $21 \%$ with a score of 23 on day 4 . These results support the findings of a previous report on the enhancement of the neutrophil functions in MDS by GCSF (12), and reveal that even MDS patients with extremely low NAP activity levels still retain the capacity to respond to G-CSF and show significant elevations of NAP activity.

In conclusion, MDS patients with absent or extremely low levels of NAP activity show varying degrees of hypogranular neutrophil morphology; however, such cases are not necessarily associated with frequent infectious complications.

\section{The authors state that they have no Conflict of Interest (COI).}

\section{Acknowledgement}

We thank Dr. M Ohmori, Department of Clinical Laboratory, Kyoto University, for the flow cytometric assessment of neutrophils.

\section{References}

1. Lowenthal RM, Marsden KA. Myelodysplastic syndromes. Int J Hematol 65: 319-338, 1997.

2. Vardiman JM, Thiel J, Arber DA, et al. The 2008 revision of the World Health Organization (WHO) classification of myeloid neoplasms and acute leukemia: rationale and important changes. Blood 114: 937-951, 2009.

3. Greenberg PL, Tuechler H, Schanz J, et al. Revised international prognostic scoring system (IPSS-R) for myelodysplastic syndromes. Blood 120: 2454-2465, 2012.

4. Martin S, Baldock SC, Ghoheim ATM, Child JA. A defective neutrophil function and microbicidal mechanisms in the myelodysplastic syndromes. J Clin Pathol 36: 1120-1128, 1983.

5. Boogaerts MA, Nellissen V, Roelant C, Goossens W. Blood neutrophil function in primary myelodysplastic syndromes. $\mathrm{Br} \mathrm{J}$ Haematol 55: 217-227, 1983.

6. Ruutu P. Granulocytic function in myelodysplastic syndromes. Scand J Haematol Suppl 45: 66-70, 1986.

7. Bendix-Hansen K, Kerndrup G. Myeloperoxidase-deficient polymorphonuclear leukocytes. (V): Relation to FAB-classification and neutrophil alkaline phosphatase activity in primary myelodysplastic syndromes. Scand J Haematol 35: 197-200, 1985.

8. Ohsaka A, Saionji K, Watanabe N, et al. Complement receptor type 1 (CR1) deficiency on neutrophils in myelodysplastic syndrome. Br J Haematol 88: 409-412, 1994.

9. Inagaki N. Superoxide anion $\left(\mathrm{O}^{2-}\right)$ production by neutrophils in myelodysplastic syndromes (MDS). Acta Med Okayama 105: 919932, 1993 (in Japanese).

10. Strauss RG, Bove KE, Jones JF, Mauer AM, Fulginiti VA. An anomaly of neutrophil morphology with impaired function. $\mathrm{N}$ 
Engl J Med 290: 478-484, 1974

11. DeChatelet LR, Shirley PS, McCall CE, Bass DA. Dissociation of leukocyte alkaline phosphatase from the bactericidal activity of neutrophils. Infec Immunity 23: 94-98, 1979.
12. You A, Kitagawa S, Okabe T, et al. Recombinant human granulocyte colony-stimulating factor repairs the functional abnormalities of neutrophils in patients with myelodysplastic syndromes and chronic myelogenous leukemia. Blood 70: 404-411, 1987.

(C) 2013 The Japanese Society of Internal Medicine http://www.naika.or.jp/imonline/index.html 